\title{
Single space transforaminal lumbar interbody fusion in spondylolisthesis: initial experience of 30 cases
}

\author{
Islam MA, Sakeb N, Sarker SK \\ Department of Orthopaedic Surgery, Bangabandhu Sheikh Mujib Medical University, Dhaka. \\ Email: maislam.spine@gmail.com
}

\begin{abstract}
Spondylolisthesis in adults is characterized by the loss of disc height across the affected segment with sagital translation. The goal of stabilizing the spine is accomplished by fusion. Transforaminal approach for lumbar interbody fusion is a very good approach and reduces the complications associated with traditional posterior approach. It has been reported to be safe and effective in the treatment of spondylolisthesis. It has done to assess the functional outcome of Transforaminal Lumbar Interbody Fusion (TLIF) in spondylolisthesis. This prospective interventional study was performed from July 2008 to June 2011 included 30 patients (male 07, female 23), within a age range of 30-59 years. Nineteen cases were lytic, 08 cases were degenerative, 02 were post-traumatic and 01 dysplastic variety of spondylolisthesis. Follow up ranged from 12 to 24 months and outcome assessed by VAS and ODI regarding pain and disability. Achievement of fusion and complications were documented accordingly. Statistical analysis was done by unpaired t-test and chi-squared test in appropriate instances. We included twenty 0ne $\left(70.00 \%\right.$ ) patient had Grade-II Spondylolisthesis and $\mathrm{L}_{4}$ over $\mathrm{L}_{5}$ had been the commonest level $(53.33 \%)$ involved. Pain and disability improved significantly and 22 $(73.33 \%)$ patients returned to their previous level of activity. One (03.33\%) patient developed superficial wound infection and $01(03.33 \%)$ had persistent low back pain. All patients had neurological improvement. We concluded that Transforaminal Lumbar Interbody Fusion is an effective alternative surgical procedure for the treatment of spondylolisthesis. Overall outcome is satisfactory in $93.33 \%$ cases.
\end{abstract}

\section{Introduction}

Spondylolisthesis is a common condition and is defined as the forward shift of the spinal column ${ }^{1}$ which is characterized by a failure of the threecolumn support with severe complex instability requiring reconstruction ${ }^{2}$. The extent of the slip is usually graded using the Meyerding classification ${ }^{3}$ in which the displacement of one vertebral body on another is divided into four equal parts. Grades I and II represent up to $25 \%$ and $50 \%$ displacement respectively and cover the majority of cases, are referred to as low-grade slips. The initial management of the condition is conservative. When this is deemed to have failed, surgery is considered. Surgery is indicated to prevent further progression of slip, to relief back and leg pain, reverse the neuro-deficit and stabilize the segment ${ }^{4}$. Posterolateral fusion has long been considered the "gold standard" for surgical treatment of adult spondylolisthesis. Superior results have subsequently been reported with interbody fusion with cages and posterior instrumentation 5 .

Interbody fusion techniques have been developed to provide solid fixation of spinal segments while maintaining load-bearing capacity and proper disc height ${ }^{6}$. The ability to reconstruct the anterior column is important because $80 \%$ of the compressive, torsion, and shear forces are transmitted through the anterior column ${ }^{7}$. The two methods of achieving an interbody fusion from a posterior approach are Posterior Lumbar Interbody Fusion (PLIF) and Transforaminal Lumbar Interbody Fusion (TLIF) ${ }^{8}$. Since Harms and Rolinger ${ }^{9}$ introduced transforaminal lumbar interbody fusion (TLIF), TLIF has been performed as an alternative to conventional posterior lumbar interbody fusion (PLIF) ${ }^{\mathbf{1 0}}$. TLIF is an alternative interbody fusion procedure in which interbody space is accessed via the far lateral portion of the vertebral foramen ${ }^{11}$. It has several advantages over other fusion methods ${ }^{\mathbf{1 2}}$ and the clinical outcomes associated with TLIF have been reported to be comparable to those of PLIF or Anterior Lumbar Interbody Fusion (ALIF) ${ }^{\mathbf{1 3}}$ and has been reported to gain popularity world wide ${ }^{\mathbf{1 4}}$.

This technique is very new in Bangladesh and performing in our University and other private hospitals. We have performed this study with an aim to assess the outcome of TLIF in Spondylolisthetic cases. 


\section{Materials and Methods}

This prospective interventional study was performed from July 2008 to June 2011 in our official and private setup. The patients with unstable Spondylolisthesis grade I-II were included but with the followings were excluded: i) Spondylolisthesis > grade II; ii) Previous history of spondylo-discitis; iii) Medically unfit patients. We included 30 patients (male 07, female 23); within an age range of 30-59 years. All the patients were evaluated preoperatively by $\mathrm{X}$-ray L/S spine $\mathrm{A} / \mathrm{P}$, Lateral [Figure-1(a) and Figure-2(a)] and oblique view. Flexion- extension films were done to assess the instability. MRI of the L/S spine [Figure -1(b) and Figure -2(b)] was done routinely to delineate the intra spinal neurological condition. Nineteen cases were lytic, 08 cases were degenerative, 02 were post-traumatic and 01 dysplastic variety of spondylolisthesis. The $\mathrm{L}_{4 / 5}$ level was involved in 17 cases, $\mathrm{L}_{5} / \mathrm{S}_{1}$ level in 10 cases and $\mathrm{L}_{2 / 3}$ level in 03 cases. Fourteen patients had sensory involvement, 10 patients had motor involvement and 05 had loss of reflexes.

Follow ups: Follow up ranged from 12 to 24 months and outcome assessed regarding pain, disability and achievement of fusion. All the cases were evaluated both preoperatively and postoperatively regarding the clinical outcome and improvement of pain and disability status. Follow up was consecutively at 3 months, 6 months and 12 months followed by 6 months interval thereafter. All the patients were evaluated clinically to assess the neurological status.

Assessment: We assessed the patients with Visual Analogue Score (VAS) ${ }^{\mathbf{1 5}}$ and Oswestry Disability Index (ODI) ${ }^{16}$ at every follow-up. Every patient had done check X-ray L/S spine $\mathrm{A} / \mathrm{P}$ and lateral view [Figure-1 (d), (e) and Figure-2 (d), (e)] and send to a radiologist for comments about the fusion status with blinding. Computed Tomography (CT) scan had been reserved for cases where radiological fusion was doubtful or in cases with pseudoarthrosis. The patients were documented with the standard VAS and ODI questionnaire to assess the improvement of the pain and disability status in every follow-up. We have graded the

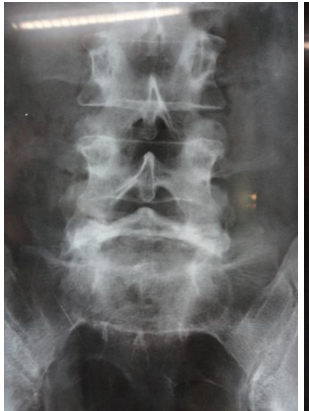

(a)

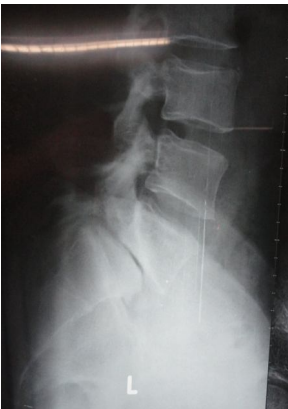

(b)

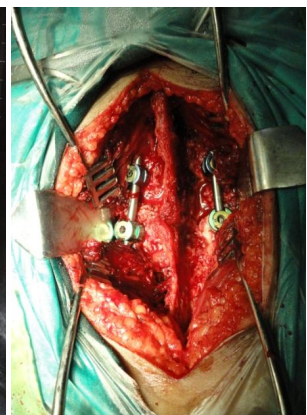

(c) overall comprehensive outcome of the study by the Macnab`s criteria ${ }^{\mathbf{1 7}}$ as follows; Excellent: Full recovery of symptoms and no restriction of occupational or daily activities; Good: Residual or occasional symptoms but able to continue normal activities; Fair: Partial recovery of symptoms, unable or difficulty to continue work; Poor: No recovery or worsening of symptoms. Statistical analysis was done by unpaired t-test and chisquared test in appropriate instances.

The operative technique: We used the posterior midline incision followed by subperiosteal muscular dissection. The lateral margin of the facet joints as well as the transverse processes was identified to determine the site of pedicle. Pedicle screws were inserted using the freehand technique and checked for proper placement by C-arm. Unilateral laminotomy and partial facetectomy were performed on the side consistent with the patient's symptoms. The disc space was gradually distracted by using the pedicle screws and rods with distractors. Annulotomy done over the posterolateral portion of the annulus and the entire discs were removed. Endplates was curetted out by the specially designed box currettes with carefully protecting the thecal sac and nerve roots. We took the morcelized bone grafts from the excised spinous process and parts of laminae and introduced to the anterior part of the disc space and impacted with an impactor. The serial cage template was inserted and the interbody cage of appropriate size, packed with bonegraft was placed within the space and checked for proper positioning. Once the cage with graft has been placed, pedicle screws are then attached to lordotic rod [Figure-1(c) and Figure-2(c)] and compressed to restore the lumbar lordosis. The exiting nerve roots were decompressed and the traversing roots were checked for any residual compression. Laminae and the remaining contralateral facet joint are decorticated, and packed with local autologous graft taken from the excised spinous process and part of laminae. The lateral intertransverse space was also packed and wound was closed with a drain insitu.

Fig.1: Patient with grade-II Spondylolisthesis with instability at $\mathrm{L}_{5}$ over $\mathrm{S}_{1}$. The preoperative A/P and lateral view of L/S spine (a,b); The intraoperative view of instrumentation (c); The A/P film showing the sagittal orientation of hardware (d); The Postoperative lateral film showing restoration of anatomy and good position of hardware (e). 


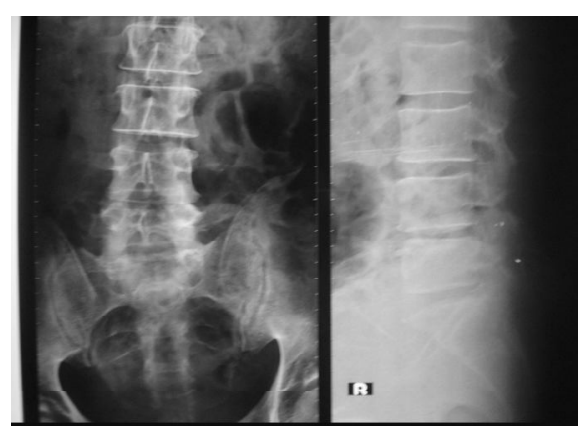

(a)

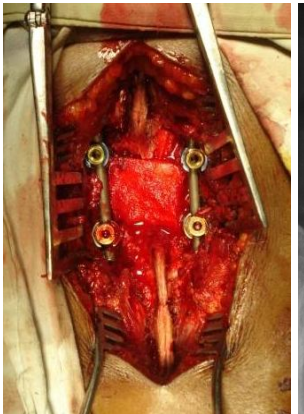

(c)

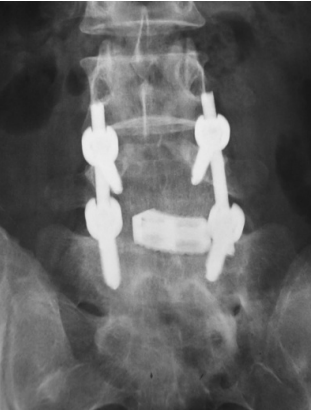

(d)

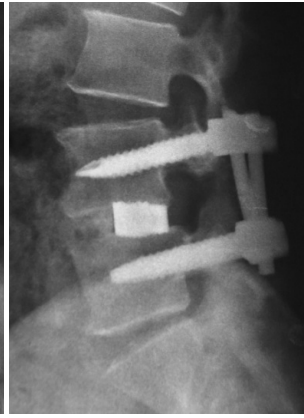

(e)

Fig. 2: Patient with grade-I Spondylolisthesis with instability at $\mathrm{L}_{4}$ over $\mathrm{L}_{5}$. The preoperative $\mathrm{A} / \mathrm{P}$ and lateral view of $\mathrm{L} / \mathrm{S}$ spine $(\mathrm{a}, \mathrm{b})$; The intraoperative view of instrumentation (c); The A/P film showing the sagittal orientation of hardware at 1 year follow up (d); The lateral film of same follow up showing restoration of anatomy and good position of hardware and achievement of fusion (e).

\section{Results}

The prospective interventional study was carried out in Department of Orthopaedic Surgery, Bangabandhu Sheikh Mujib Medical University, Shahbag and other private hospital in Dhaka from July 2008 to June 2011. Total 30 cases, age ranging from 30 to 59 years, mean age $46.75 \pm 05.65$ years were included. Maximum $18(60.00 \%)$ patients were in 40-49 years age group followed by $10(33.33 \%)$ patients in 50-59 years age group. Out of these patients $23(76.67 \%)$ were female, male: female ratio 1:3.67 with a female predominance $(\mathrm{p}<0.05)$. Housewives were $23(76.67 \%)$ \& other $05(16.67 \%)$ were manual workers and $02(06.67 \%)$ were sedentary workers (Table-I). There were 19 $(63.33 \%)$ cases with lytic, $08(26.67 \%)$ cases were degenerative, $02(06.67 \%)$ were post-traumatic and 01(03.33\%) dysplastic variety of spondylolisthesis. Among the patients $17(56.67 \%)$ Involved $\mathrm{L}_{4}$ over $\mathrm{L}_{5}, \quad 10(33.33 \%)$ Involved $\mathrm{L}_{5}$ over $\mathrm{S}_{1}$ and 03(07.50\%) cases Involved $\mathrm{L}_{3}$ over $\mathrm{L}_{4}$. Patients of spondylolisthesis grade-I $(25 \%$ slip $)$ found in $11(36.67 \%)$ cases, grade-II (50\% slip) was found in $19(63.33 \%)$ cases.

Table-I: Demographic variables of the patients. $(n=40)$

\begin{tabular}{|c|c|c|c|c|c|c|c|c|c|}
\hline \multicolumn{3}{|c|}{ Age (yrs.) } & Mean & \multicolumn{3}{|c|}{ Sex } & \multicolumn{3}{|c|}{ Occupation } \\
\hline Group & No. & Percent. & & & No. & Percent & & No. & Percent. \\
\hline $30-39$ years & 02 & 06.67 & & Male & 07 & 23.33 & Sedentary worker & 02 & 06.67 \\
\hline $40-49$ years & 18 & 60.00 & $46.75 \pm$ & Female & 23 & 76.67 & manual worker & 05 & 16.67 \\
\hline $50-59$ years & 10 & 33.33 & 05.65 & & & & Housewife & 23 & 76.67 \\
\hline
\end{tabular}

All the patients were followed up in a period for minimum 12 months. Table-II describes, 18 $(60.00 \%)$ patients had preoperative radiculopathy but post operatively all the patients significantly $(p<0.05)$ improved from their preoperative status and had no residual radicular involvement at 1 year. Preoperatively 14 (46.67\%) patients had sensory, $10(33.33 \%)$ patients had motor and $05(16.67 \%)$ patients had loss of reflexes but all of them recovered postoperatively to normal status $(p<0.05)$. The pain intensity of all the patients was assessed by Visual Analogue Score (VAS) and all the patients had significant improvement of low back pain and leg pain status post-operatively. As in Figure-3 the mean preoperative low back pain score was $07.75 \pm 02.67$ which was improved postoperatively $02.25 \pm 01.45(\mathrm{p}<0.05)$ at 1 year. The mean preoperative leg pain score was $05.25 \pm 02.54$ which was improved postoperatively $01.75 \pm 00.85$ $(\mathrm{p}<0.05)$ at 1 year. The mean preoperative disability score by Oswestry Disability Index (ODI) was $56.75 \pm 07.83$ which was improved significantly to $09.81 \pm 02.65$ at 1 year follow up $(\mathrm{p}<0.05)$ and 29 patients returned to their previous level of activity. The duration of the hospital stay ranged from 05 to
13 days, mean $06.25 \pm 03.35$ days. Fusion was achieved within 6 months postoperatively at $23.25 \pm 04.75$ weeks. One $(03.33 \%)$ patients had superficial wound infection and 01(03.33\%) patient had persisted low back pain. Satisfactory results were achieved in $37(93.33 \%$ ) cases.

Table-II: Preoperative, postoperative and outcome status of the patients. $(n=40)$

\begin{tabular}{|c|c|c|c|}
\hline \multicolumn{2}{|c|}{ Outcome variables } & Preoperative & $\begin{array}{c}\text { Postoperative } \\
\text { (at } 1 \text { year) }\end{array}$ \\
\hline \multicolumn{2}{|c|}{ Low back pain } & $30(100 \%)$ & $01(03.33 \%)$ \\
\hline \multicolumn{2}{|c|}{ Radiculopathy } & $18(60.00 \%)$ & $00(00.00 \%)$ \\
\hline \multirow{3}{*}{$\begin{array}{l}\text { Neurological } \\
\text { status }\end{array}$} & $\begin{array}{c}\text { Motor } \\
\text { involvement }\end{array}$ & $10(33.33 \%)$ & $00(00.00 \%)$ \\
\hline & $\begin{array}{c}\text { Sensory } \\
\text { involvement }\end{array}$ & $14(46.67 \%)$ & $00(00.00 \%)$ \\
\hline & $\begin{array}{c}\text { Reflex } \\
\text { involvement }\end{array}$ & $05(16.67 \%)$ & $00(00.00 \%)$ \\
\hline \multicolumn{4}{|c|}{ Functional and radiological outcome } \\
\hline Variables & Assessment Criteria & Preoperative & $\begin{array}{c}\text { Postoperative } \\
\text { (At 1year) }\end{array}$ \\
\hline $\begin{array}{l}\text { Low Back } \\
\text { Pain }\end{array}$ & $\begin{array}{l}\text { Visual Analogue } \\
\text { Score (VAS) }\end{array}$ & $07.75 \pm 02.67$ & $02.25 \pm 01.45$ \\
\hline Leg Pain & & $05.25 \pm 02.54$ & $01.75 \pm 00.85$ \\
\hline Disability & $\begin{array}{l}\text { Oswestry Disability } \\
\text { Index (ODI) }\end{array}$ & $56.75 \pm 07.83$ & $09.81 \pm 02.65$ \\
\hline \multicolumn{4}{|c|}{ Comprehensive outcome according to Macnab`s criteria } \\
\hline $\begin{array}{l}\text { Excellent } \\
\text { Good }\end{array}$ & $\begin{array}{l}20(66.67 \%) \\
08(26.67 \%)\end{array}$ & Satisfactory & $28(93.33 \%)$ \\
\hline Fair & $02(06.67 \%)$ & & \\
\hline Poor & $00(00.00 \%)$ & Unsatisfactory & $02(06.67 \%)$ \\
\hline
\end{tabular}




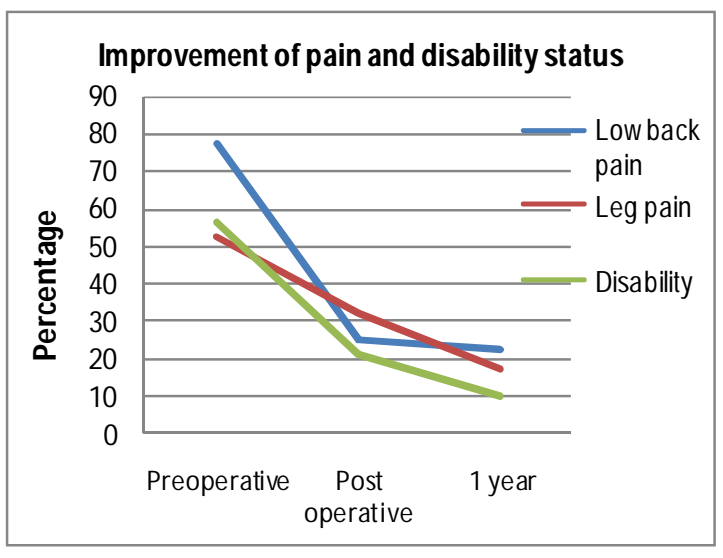

Figure-3: Improvement of pain and disability status

\section{Discussion}

TLIF is a very good alternative technique which can theoretically prevent typical disadvantages of those seen in anterior and posterior lumbar interbody fusion ${ }^{18}$. Hee et al ${ }^{19}$ compared TLIF with combined anterior and posterior fusion concluding that TLIF patients had a shorter operative time, less blood loss and shorter hospital stay compared to single stage anterior and posterior fusion. Humphreys et $\mathrm{al}^{\mathbf{2 0}}$ compared Posterior Lumbar Interbody Fusion (PLIF) and TLIF showing that TLIF had a much lower complication rate. Brislin and Vaccaro ${ }^{21}$ have reported lower risk of nerve tethering in TLIF compared to traditional PLIF. These study reports had definite influence regarding the adoption of TLIF as a surgical method of choice. The operating time was 190 minutes averaged in our series and preoperative blood loss in our single level surgical intervention was average $215 \mathrm{ml}$ and required only 1 unit of blood transfusion almost in every case. We ended up with superficial wound infection in 02 cases which were improved by broad spectrum antibiotic administration according to sensitivity report and regular dressing. One case needed debridement. Elmasry et al ${ }^{22}$ ended up with $01(03.33 \%)$ case of superficial wound infection and another 01(03.33\%) with postoperative transient paraesthesia. None of our cases had neurological involvement postoperatively. Hospital stay was $06.25 \pm 03.35$ days postoperatively which is also comparable to different other series.

In our series there were 07 male and 23 female within an age range of 30-59 years. The mean age was $46.75 \pm 05.65$ years and male to female ratio 1:3.67 showing a female predominance. Our series shows results contrary to Elmasry et $\mathrm{al}^{22}$ who showed male dominance (13 females and 17 male) in his series. We have performed only single level surgery where $17\left(56.67 \%\right.$ ) cases were at $\mathrm{L}_{4 / 5}$ comparable to Elmasry et $\mathrm{al}^{22}$ (20 out of 33). Even with 19(63.33\%) cases with grade-II and $11(36.67 \%)$ cases with grade-I unstable spine, overall $18(60.00 \%)$ patients had preoperative neurological involvement indicating a relatively advanced presentation but complete recovery at 1 year follow-up. All patients had significantly improved low back pain and leg pain status as well as the disability status at 1 year. Sebastian et $\mathrm{al}^{\mathbf{2 3}}$ also showed reduction of disability score from preoperative $23.50 \%$ to postoperative $13.50 \%$ which is comparable to ours.

All (100\%) of our patients achieved fusion within 6 months postoperatively at $23.25 \pm 04.75$ weeks. These cases were evaluated by CT scan at 6 months follow up determining adequate achievement of fusion. All the patients returned to their previous level of activity except 01 with infection requiring debridement. The patient needed occasional analgesics to get relieved from pain which was limiting his level of activity. Satisfactory (Excellent and good) results were achieved in 37 (93.33\%) cases. Elmasry et $\mathrm{al}^{22}$ reported $90 \%$ excellent or good result with $91 \%$ fusion in his series of 30 patients with low grade spondylolisthesis treated by TLIF. Yehya ${ }^{23}$ found $73.30 \%$ excellent and $26.70 \%$ good result with TLIF in 30 patients with spondylolisthesis. Lowe et $\mathrm{al}^{24}$ reported $85 \%$ good and excellent clinical results, with $90 \%$ radiological fusion in his series of TLIF with two cages.

The study had limitations because we had no cases to include with unstable upper lumbar spondylolisthesis or even multiple level instabilities requiring fusion, without which a rational conclusion of using TLIF is difficult to determine. A larger sample size with a long period study might include such cases. The period of study is not sufficiently long to conclude regarding more specified outcome regarding the hardware and its long-term functional and structural effect. Studies with larger population comparing with the specialized centers would help to find out even more advanced method of surgical management.

Conclusion: Transforaminal lumbar interbody fusion is an effective method for surgical management of low grade spondylolisthesis. The complications rate is less and provides good fusion and functional outcome.

\section{References}

1. Solomon L, Warwick DJ, Nayagam S, editors. The Back. In: Apley`s system of Orthopaedics and Fractures. $8^{\text {th }}$ ed. London: Arnold; 2001. p.397.

2. Fredrickson BE, Baker D, McHolick WJ. The natural history of spondylolysis and spondylolisthesis. J Bone Joint Surg Am. 1984; 66: 699-707. 
3. Meyerding HW. Spondylolisthesis. Surgical treatment and results. Surg Gynecol Obstet. 1932; 54: 371-7.

4. Kraft CN, Krauspe R. Spondylolisthesis. In: Boos N, Aebi M, editors. Spinal Disorders: Fundamentals of Diagnosis and Treatment. Berlin: Springer; 2008. p. 733-96.

5. Dehoux E, Fourati E, Madi K, Reddy B, Segal P. Posterolateral versus interbody fusion in isthmic spondylolisthesis : functional results in 52 cases with a minimum follow-up of 6 years. Acta Orthop Belg. 2004; 70: 578-82.

6. Stonecipher T, Wright S. Posterior lumbar interbody fusion with facet-screw fixation.Spine 1989;14:468-71.

7. Ishihara H, Osada R, Kanamori M et al. Minimum 10year follow up study of anterior lumbar interbody fusion for isthmic spondylolisthesis. J Spinal Disord 2001; 14: 91-9.

8. Xiao Y, Chen Q, Li F. Unilateral Transforaminal Lumbar Interbody Fusion: a Review of the Technique, Indications and Graft Materials. J Int Med Res. 2009; 37: 908-17.

9. Harms J, Rolinger H. A one-stage procedure in operative treatment of spondylolisthesis: Dorsal traction-reposition and anterior fusion. Z Orthop Ihre Grenzgeb. 1982; 120: 343-7.

10. Kwon BK, Berta S, Daffner SD, Vaccaro AR, Hilibrand AS, Grauer JN, et al. Radiographic analysis of transforaminal lumbar interbody fusion for the treatment of adult isthmic spondylolisthesis. J Spinal Disord Tech. 2003; 16: 469-76.

11. Brislin B, Vaccaro AR: Advances in posterior lumbar interbody fusion. Orthop Clin North Am. 2002; 33: 367-74.

12. Rosenberg WS, Mummaneni PV. Transforaminal lumbar interbody fusion: technique, complications, and early results. Neurosurgery $2001 ; 48: 569-74$.

13. Potter BK, Freedman BA, Verwiebe EG, Hall JM, Polly DW Jr, Kuklo TR: Transforaminal lumbar interbody fusion : clinical and radiographic results and complications in 100 consecutive patients. J Spinal Disord Tech. 2005; 18: 337-46.

14. Cole CD, McCall TD, Schmidt MH, Dailey AT. Comparison of low back fusion techniques: transforaminal lumbar interbody fusion (TLIF) or posterior lumbar interbody fusion (PLIF) approaches. Curr Rev Musculoskelet Med. 2009; 2: 118-26.

15. Guyatt GH, Townsend M, Berman LB, Keller JL. A comparison of Likert and visual analogue scales for measuring change in function. J Chronic Dis. 1987; 40: 1129- 33 .

16. Walsh TL, Hanscom B, Lurie JD, Weinstein JN. Is a condition-specific instrument for patients with low back pain/leg symptoms really necessary?: The responsiveness of the Oswestry Disability Index, MODEMS, and the SF-36. Spine (Phila Pa 1976) 2003; 28(6): 607- 15.

17. Macnab I. Negative disc exploration. J Bone and joint surg. 1971; 53(5): 891-901.

18. Lauber S, Schulte TL, Liljenqvist U, Halm H, Hackenberg L. Clinical and radiologic 2-4-year results of transforaminal lumbar interbody fusion in degenerative and isthmic spondylolisthesis grades 1 and 2. Spine 2006; 31: 1693-8.

19. Hee HT, Castro FP Jr, Majd ME, Holt RT, Myers L. Anterior/posterior lumbar fusion versus transforaminal lumbar interbody fusion: analysis of complications and predictive factors. J Spinal Disord. 2001; 14: 533- 40.

20. Humphreys SC, Hodges SD, Patwardhan AG, Eck JC, Murphy RB, Covington LA. Comparison of posterior and transforaminal approaches to lumbar interbody fusion. Spine 2001; 26: 567-71.

21. Brislin B, Vaccaro AR. Advances in posterior lumbar interbody fusion. Orthop Clin North Am. 2002; 33: 367- 74 .

22. Elmasry MA, Khayal H, Salah H. Unilateral transforaminal lumbar interbody fusion (TLIF) using a single cage for treatment of low grade lytic spondylolisthesis. Acta Orthop. Belg. 2008;74, 667-71.

23. Yehya A. TLIF versus PLIF in the management of Spondylolisthesis. Bull. Alex. Fac. Med. 2010; 46(2): 127-33.

24. Lowe TG, Tahernia AD, O'Brien MF, Smith DA. Unilateral trans-foraminal posterior lumbar interbody fusion (TLIF): indications, technique, and 2-year results. J Spinal Disord Tech. 2002; 15: 31-8. 